\title{
Making of Tradition: Perspectives on Hindu-Muslim Relations in Andaman and Nicobar Islands
}

\author{
Kanwar Chanderdeep Sing* \\ Department of Historical Studies, JNR Mahavidyalya Port Blair, Andaman and Nicobar Islands
}

*Corresponding author: Kanwar Chanderdeep Sing, Department of Historical Studies, JNR Mahavidyalya Port Blair, Andaman and Nicobar Islands

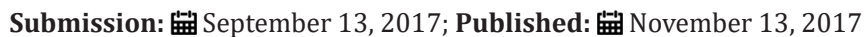

\section{Introduction}

The making of traditions is often a conscious or a non conscious exercise wherein the centripetal forces of history, culture, shared sorrows and happiness, longings and belongings play constructive roles. Many a time the made traditions blunt the divide of origin of the otherwise varied communities distinct from each other by ethnicity, language, religion and in some other minor aspects. The society and culture of a particular space and time often reflects the mooring of the people who live in those times and spaces. It is particularly apt for those groups of people and places which/ who do not have a very long history to remember and cherish. The place called Andaman and Nicobar Islands presents such a picture and give such an impression. This essay therefore tries to explore the inter-communal relations involving the Hindu and the Muslims of Andaman and Nicobar Islands and what factored these communities to live in amity in spite of marked communal conflagrations in different parts of India. I also intend to present an overview of the geo cum socio-cultural environs of these Islands which strategically are one of the most vital and sensitive regions of India.

There are simple but curious questions that arise out of dabbling with the concept of 'invented traditions' in context of Andaman and Nicobar Islands. Foremost, why there is a need to study these invented traditions? More so, why should a scholar from the discipline of history study it at all? Why not any social anthropologist? The pertinence of these problems draws a historical inquiry into it. The invented traditions of any society in any spatial time frame are indicative of different socio-psychological undercurrents. The problem of unavailability as well as intangibility of the sources to construct past can therefore be eased by the study of such invented practices. There may be reasons to the differential functionality of the traditions. The Andaman traditions also need to be studied to get a fair idea of people's past who migrated or brought to this place even at the cost of severing cultural and kinship ties. Here arises the role of a historian who dugs into the historical legitimacy of newly invented traditions at a newer place doing juxtapositional exercises vis a vis the past and present. To invoke Hobsbawm, who has decoded thus about the threesome invented traditions- a) Those establishing or symbolizing social cohesion or membership of groups, real or artificial communities.

b) Those establishing the legitimacy of institutions, status or relations of authority.

c) Those whose main purpose was socialization, inculcation of beliefs, value systems and conventions of Behavior [1].

d) These aspects in varying degrees can be seen in the sociocultural milieu of Island society.

As far as the ANI is concerned nothing substantial has been said about the phenomenon of invented traditions and hence an appropriate social discourse has not been set or at least adequately investigated. This place though has many communal and ethnic groups and Problematization of all may not fit to the size of a limited length academic paper. Hence I shall focus majorly on two of the three largest communities of these Islands; the Hindus and Muslims (the third one being Christians) and their made (invented) traditions. What are the socio- cultural traditions that have bonded the people together despite the overwhelming religious markers scattered all around the Islands particularly in the capital city of Port Blair? Particularly, these markers elsewhere in India have a chequered record of contributing to communal antagonisms.

Communally diverse and charged country as India has become since the beginning of 20th century, the inter-faith relations have always been an issue of intense debates and contestations. The two most important communities or religions of this nation that are more often in the centre stage of discourse on communal harmony and acrimony are the Hindus and Muslims. Not long before, the Shuddhi versus Tabligh and Sangathan versus Tanzeem like movements created conducive atmosphere for communal polarisations in British India and pitted the Hindus and Muslims against each other. The socio-religious reform movements of late 19th and early 20th centuries hence were one of the biggest contributors towards the deterioration of inter-communal relations in pre-independence India, other being the British. The British benefited from pitting Hindus and Muslims against one another and portrayed themselves as neutral saviours who could 
keep ancient religious conflicts at bay [2]. When the bad politics fed on radicalisation, the resultant effect was the partition of India on communal lines. It is also believed that most of communal conflicts in modern India have either fuelled by the ideological assumptions, mythical or historical and by the politics of mollification. Various politico-religious issues like the cow-protection, uniform civil code and proselytization have furthered the antagonizing tendencies between them. The pre- independence Jinnah-nian notion of Hindus and Muslims being separate nations therefore still echoes in some sections of the people and the ideal of secularism is still struggling to find its true definition in Indian context.

A noted writer and journalist Francois Gautier with a keen eye on the Indian socio-politics thus observed,

On the surface, you cannot find two more dissimilar religions: the first one is a monotheistic faith which proclaims that Allah is the only God and all believers of other religions are to be treated as "Infidels"; and the second swears by polytheism and adores thirty millions of Gods and Goddesses... Because of these differences, both these creeds have been at loggerhead for centuries and the Muslim invasions of India have been exceptionally bloody. Today even, Islam and Hinduism collide in Kashmir, in Ayodhya, or in the wars between Pakistan and India [3].

Despite above assertion, the majority of these two majority communities who have a long shared history of more than 1200 years, the processes of acculturation have brought in them a sense of mutual agreement and acceptance.

\section{Hindus-Muslim Syncretism and Cosmopolitanism of Andamans}

Andaman and Nicobar Islands' tryst with modernity began with the settlement at Chatham Island in 1787 when the British Government of Bengal set up her naval base. However it was abandoned shortly due to the hostile living conditions predominantly due to malaria. In the wake of the rebellion of 1857, the British again decided to resettle these Islands with the convicts on more durable and permanent basis in 1858. The high point of the colonial tradition of crime and punishment culminated in the form of construction of the Cellular Jail in 1906 (started in 1896). The process of influx of outsiders that started off with the penalising intent did not stop with the end of colonial rule. In the decolonised India it continued unabated, though the nature and character of immigration changed and so were the dimensions. In the wake of pre 1942 and post 1947 migrations to these Islands its demographical profile underwent a monumental change with the sons of the soil (tribes) becoming minority. Through various policy measures the government populated these islands with the people from pan India. Predominantly, the states of West Bengal, Andhra Pradesh, Tamil Nadu, Kerala, Chotta Nagpur region and to some extent Punjab became the major contributors towards this cause of 'Indianisation' of these Islands. In the present times, at best, the social fabric of ANI can be described as cosmopolitan.

The communities which came to these Islands pre and post
Independence brought with them the slices of their culture and heritage and thus laid the foundation of a new synthetic culture. This culture was the healthy concoction of the several pan Indian traditions which hitherto had not tasted each other. So the phenomenon of formation of the Andamanes society is not of a distant past and was a process primarily and loosely started after the colonization. The evolution of ANI first as a penal colony and later on as a Union Territory presents a picture of cultural universalism and relative similitude. In spite of the seemingly different communities that inhabit these Islands, they mostly converge on varied aspects of social and communal life. Along with carrying the baggage of their past native places they have successfully metamorphosed themselves in accordance with norms of a cosmopolitan society. An unintended legacy of colonial rule, both British and a brief Japanese interlude (1942-1945) was the cultural and communal harmonization. The acculturative phenomenon mentioned in the preceding paragraphs therefore seems more pronounced in these Islands than anywhere else in the country. There are varied plausible factors to this blending of traditions.

According to the Census of 2011 the number of Hindus and Muslims in ANI are 264296 and 32413 respectively which makes them around $69.45 \%$ and $8.52 \%$ of the total population. Although, the Hindus and the Muslims are among the biggest communities, they are seldom homogeneous. Both communities could trace their antecedents to diverse geo-cultural regions of the Indian subcontinent. Saving the tribal, the ex-convicts of different religious dispensations and their descendents (Local Borns) are the earliest settlers of these Islands. Thus, the people from both the communities were brought from different parts of India as convicts as well as free settlers. However at several specific junctures in the history of these Islands the influx of Hindus and Muslims was the greatest. First instance came in the aftermath of Moplah rebellion in the Malabar region from 1921 to 1923 when large numbers of Muslim Moplah convicts were incarcerated to Andaman and lead to a big surge in the Muslim population. The second important surge was led by the deportation of the members of Bhantu community, mainly Hindus purportedly of Kshatriya lineage. The third upsurge came immediately after the Partition of India when the displaced Bengalis (majorly Hindus) from East Pakistan were rehabilitated in the Islands in 1949 followed by a Five Year Colonization plan that begun in 1952 [4].

Such migrations to the Islands in the wake of Partition of India, particularly from East Pakistan, alarmed the local people and generated a sense of insecurity of being marginalized by becoming minority. It had its affect on communal harmony and aggravated racial tensions. The next influx, though somewhat illegal, came in the wake of the formation of Bangladesh in 1971-72 and many Muslims apart from the Hindus managed to get permanent shelter here. In addition to the above mentioned, various settlers from South India like from the states of Travancore-Cochin and Madras have contributed towards the demographic fulfillment of ANI.

\section{Examples of Hybridization}

The hybridization of society with strong inter-faith linkages can 
be vividly seen in the common life of the populace. The examples are galore which represent such hybridization. Broadly speaking, such intermingling could be understood by looking at four different facets of social life viz. matrimony, culinary and dietary habits, language and festival celebration.

Marriage is such a social institution in India where the norms are strongly guided by the communal and caste customary practices. Any digression from the established normative behavioral codes expectedly generates strong reactions. A country where the honor killings are still rampant and are accepted as a way of redeeming family and community pride among the sections of society, ANI present a stark non conformist picture. The extent to which interfaith marriage is possible and the degree of social and religious institutions' acceptance of interfaith couples indicate the breadth and depth of social pragmatism. The tradition of interfaith marriages goes back to 1870s when the contact between free settlers continued and self supporters expanded [5]. The number of marriages in the penal settlement rose sharply as a result from 69 in 1876-1877 to 109 in 1877-1878. Inter-marriages between free settlers and self-supporters was fundamentally inconsistent with policies of segregation but given the centrality of marriage to rehabilitation scheme in Andamans, the regime willingly compromised on segregation.5 There was shortage of women before and after independence which proved like blessing in a way. Since the women were few and therefore the men had very little choice. There were the instances of Hindus marrying Buddhists, Buddhists marrying Muslims, Muslims marrying Sikhs [6]. The trend initiated because of the exigencies of penalty and survivals continued in the 20th century and well post 1947.

Even in the far flung tribal Nicobar group of Islands the interfaith matrimony is quite rampant among the tribal, either Christian or Muslim or a Hindu animist. The conversions based on these marriages are taken in stride without any associated outrage or il will against the other, a phenomenon uncommon to the mainland India. It has been observed in a study regarding the socio-cultural aspects of the locals where a divorced Hindu woman married a Muslim and then got children from her Muslim husband. The children from her previous Hindu husband were visiting temple with the mother and the children from her Muslim husband were visiting mosque and observed Muslim rituals, no confrontation was ever reported [7]. In a same family we may have a Hindu husband, a Muslim wife and Christian cousins. The Andaman experience thus shows that marrying someone of another faith tends to improve one's view of that faith bringing about harmonization based on heterogeneity.

The food in these Islands is a great conglomerateur. Generally, it is believed that the Hindus tend to lean more towards vegetarianism whereas the Muslims are ubiquitously non-vegetarians. However, the geography, limited availability of vegetables as well as heavy cross-cultural interactions has significantly altered the dietary habits of the locals of all faiths. When compared to the mainland more percentage of Hindus have adopted non-vegetarian dietary habits. Even Biryanis in these Islands do not distinguish between the
Hindus or the Muslims or for that matter the Christians. Ubiquitous consumption of the halal non vegetarian food (ungrudgingly even by the Hindus) is another point of cultural synthesis and accommodation. All the prominent Indian festivals are celebrated with equal camaraderie irrespective of their being belonging to the other side of communal spectrum. While my fieldwork I came across two peculiar spectacles of Ganesha Visarjan and Durga Visarjan wherein the jubilant crowd accompanying these twin processions were curiously inter-communal. Dancing to the film tunes, they scrupulously merged their identities to a common whole bothering the least about the segregative popular understanding of their religions. The point I intend to make is that the similar occasions at several places in mainland it had historically been the harbinger communal riots between the Hindus and Muslims [8].

The ANI is diametrically antithetical in this context.

The mother tongues of the local population are as numerous and diverse as the regions of India from where they are derived. At the time in 1950s and 1960s when India was being re-organized on linguistic basis and lingual rivalries were running large within the states, ANI emerged as a perfect prototype of a nationalism based upon language. According to the Imperial Gazetteer of India Provincial Series, Andaman and Nicobar Islands, the lingua franca of the Settlement was Urdu(Hindustani),spoken in every possible variety of corruption and with every variety of accents. It is also the vernacular of the 'local born' whatever their descent was [9]. Presently, Andaman Creole Hindi is the lingua franca in Islands and has successfully managed to cement the communal ties. It draws its vocabulary from linguistic traditions of all the communities inhabiting the Islands. In spite of great diversity in languages the unity prevails in expression which is largely facilitated by Hindustani, a fusion of linguistic pragmatism with Andamanese identity. Hence the lingual tradition has effectively managed to contain the 'us versus them' conflict which otherwise could have marred the communal solidarity as Hindi versus Urdu and Hindi versus Punjabi controversy has done in the cases of Uttar Pradesh and Punjab.

\section{Historical Antecedents}

In question is the Hindu-Muslim relationship. The imperatives that have made Hinduism and Islam to thrive together could be found in the one and half century history of the societal construct of the Islands. These communities have passed through three different phases of domination and authority which has aided in the formulation of invented traditions. The first cycle was under the British rule with its crime and punishment tautology, people getting used to it and accepting it as a tradition. The second phase constituting Japanese regime, with the tradition of less crime but more suspicion, resultant punishment and people getting abused due to that. The third phase was and is under the Indian governance with its bureaucratic stranglehold and intricacies, a natural corollary of the modern democratic set-up with an overflowing idea of nationalism. Here again the people imbibing the idea, reworked their relation with the authority and institutions and in the process 
making themselves a part of it. There are other set of traditions which are the obvious outcomes of togetherness; geographic and historic.

In the Island society, social and cultural innovations have been quite a recent phenomenon whose concretization roughly started after reduction in penalizing intent of the colonialists. These invented traditions are ostensibly relevant even today because of the presence of the element of contemporaneity in them. The language, the communal relations, demography and the shared baggage of history that people carry feed on these traditions. Had ANI been a separate state, its unity would have been a match for the Singaporean nation state, a colonial cousin which providentially had the tryst with nationalism broadly at the same time. The communal binaries of Hindu- Muslim could even had been lesser concretized. However that would have been again a constructed tradition which could have come to them naturally. The conjecture in this regard could be drawn vis a vis mainland India where both the antique traditions of Bharatvarsha as well as the concocted ones of 'Hindu Rashtra' were galvanizing the anti colonial struggle and the phenomenon of nation in making. Understandably, traditions, invented or original ones were templates on which the claims and counter claims straddle.

The people of ANI have seen the dark days of penalization under the British and even darker under the Japanese regime. This had a solidifying effect on the fraternal bondage of the people of diverse origins. If taken into account the early period of settlement of the Islands, it is found that Port Blair (which had/has single largest concentration of the population) failed to develop a genuinely collaborationist class of natives. As Satadru Sen argues that the convict subordination retained a persistent sense of solidarity with other convicts and their failure to function as reliable agents of state surveillance reflects an agenda of politically united opposition to the colonial regime [10].

This depicts that even in the initial stages of settlement in the Islands a sense of unity had started prevailing even though the aftermath of the 1857 generated much acrimony among the Hindus and the Muslims who blamed each other of sabotaging the spirit of revolt. There are two instances depicted here from many such instances where the initial Hindu-Muslim repulsiveness was explicitly discernible. As back as in 1859 writing to the Home Department, Superintendent Haughton noted the difficulty in getting Hindu convicts to eat food cooked at the Settlement hospital where the Muslim sick were treated [11]. Secondly, in the last quarter of 19th century many Wahabis were transported to ANI which helped the cause of Islamic radicalization of the Islands. In Port Blair, as elsewhere, a great resort for those desiring to raise their social status was the adoption of Islam [12]. One such Wahabi was Mohd. Jaffar Thaneshwari, who after marrying a Brahmin female convict lived in Andaman for 18 years [13]. However with time owing to the peculiar isolated insular circumstances in which the convicts lived, the process of natural de-radicalization ensued which aided in bringing forth the feeling of religious accommodation. The colonialists in the Islands kept prisoners from different communities with each other so that they should not mix with their co-religionists and hatch conspiracies. As in mainland -India, in Andaman too the British employed the divide-and-spy tactic to divide the communities and to create a loyal subservient class for themselves. The conditions under which the people lived were so artificial and much unlike those of ordinary communities that it was impossible to describe them on the usual lines [14].

This remark aims at the description of social state of convicts and the unofficial population in the regulated conditions of life imposed on them. The restrictions under which the free residents lived have a distinct effect on the characters of those subjected to them from childhood to death. This effect became more and more apparent as generations after generation of convicts' descendents come under their pressure [15]. In the colonial worldview India was a collection of the communities: self contained, inviolable groups and subgroups based on religion, profession and race [16].

Caste and religion initially took a special importance to the penal society of Andaman for two primary reasons. First, the colony was founded in the wake of the Mutiny of 1857 which had the issues of religious sensibilities like greased cartridges. The colonialists therefore were particular about the social sensibilities of the prisoners and took care of not offending them. Secondly, given the British perception of the Indian society, it was inconceivable that a viable society of Indians could be constructed in the Islands without reference to caste and religion and application of segregation based on those criteria [17].

While the British wanted to take all the social divisions into account in the construction of the penal society but they wanted to avoid the complexities of mainland. They reworked the social structure on the lines of administrative conveniences cutting the divisions down to the basic groups dictated by their comprehension of the Indian society. In fact they recreated the workable social set up. As such religion became purely a personal affair in the Islands. Resultantly the ANI grew very rapidly into a very homogeneous society. However, there remained an unresolved contradiction between the visions of Andaman as a model colonial society and the view that the Islands were a dumping ground of the mainland refuse [18]. This workable set up with limited recourse to communal affiliations ultimately forged fundamentals of the Island's society.

\section{Why and What for}

From theorization of diverse phenomena which ANI underwent since the penalization days and forging of communal amity draw some possible answers. It is believed that the common and shared miseries are more unifying forces then the shared happiness and celebrations. The people of ANI have seen the dark days of penalization under the British and even darker under the Japanese regime. Extreme conditions of terror, starvation and deprivation that prevailed diluted the barriers of religion. This had a solidifying effect on the fraternal bondage of the people of diverse ethnicities and religions. The people owing to their long distance from the mainland India have developed kind of emotional linkages which comes naturally to the people living in isolation from their native 
places. This process of integration of a variety of religious groups has produced a most interesting community of people with remarkable quickness of intellect and practical sense [19].

The growth in immensity of solitude and separation has resulted in the formation socio-cultural economy with original bias towards newness. This has given rise to a great fusion phenomenon where almost everyone knows everyone. The natural calamities like cyclones and tsunamis which are a regular feature of the Islands' climatic calendar also aids in the consolidation of these fraternal bonds. In the disaster like situations the help from the mainland which often takes time to reach press the people to reach for each other. Another strange but seemingly a valid point is the absence of strong regional political influence over the people. This may be due to the absence of provincial legislature and the regional political parties, though the parliamentary and local self government elections are fought enthusiastically. The fissiparous tendencies that regional power politics brings in its wake between the castes, religions, linguistic groups etc are seemingly less crystallized in these Islands. As in mainland India the evils of vote bank politics and tendencies of the religious groups to affiliate with one or the other political party is discernibly less concretized.

In spite of the composite culture that apparently harks on harmony there are certain silent undercurrents in the society depicting radicalizing trends. It is being observed that due to unsolicited migrations a part of which is illegal has placed more emphasis on overt religious markers. It is seemingly becoming more pronounced among the Muslim community begetting reactions from the sections of the Hindu community [20]. As one communalism feeds on the other therefore hardening of stances have become more vehement. As far as the locals of both the communities are concerned they still nurture the values of tolerance and mutual accommodation. But increasing influx of outsiders primarily of religion cultural backgrounds has subtly altered the harmonious communal equilibrium. The religion which used to be a personal affair is increasingly becoming a communal affair. Despite the dynamics of social change playing its role, the communal climate of ANI is far conducive to plural human growth in comparison to any other part of India.

\section{Conclusion}

In today's age of terror it is not unusual for a multi-religious and multi-ethnic society, which Andaman has become, to feel vulnerable of social fragmentations. Of late, there are some discernible trends pointing towards the attempts at radicalization of society. This holds a bit of truth in the wake of purported illegal influx of Bangladeshis and subtle efforts to alter the demographic profile of these Islands [21]. Still, in ANI there seems the coexistence of old nativist ethnocommunal traditions as well as the invented practices which are forged after migration to this place by the diverse people. The old traditions have made people wedded to their mainland roots and fostered the familial bondage among them. The invented ones whilst making people adaptable to the new homeland have encouraged and inculcated the esprit de corps in adjunct to communitarians- ism, rights and duties. The significant element that could be clearly demarcated is the fuzzy universalism of nationalism, subnationalism (Island nationalism), emoticons (emotional icons) and near preponderance of accommodative ideologies of Hinduism and Islam. So far the people have not allowed their religion to interfere in the secular communitarian life. The biggest gain that generates from studying such invented traditions is the understanding and interpretation of the people's past with the people's present, a transformation from penal society to a civil society. The evolution of peculiar communal traditions in a laboratory like atmosphere with historical and geographical interventions demonstrates how a secular State as well as state of mind is achieved on plurality.

The Emerald Isles, as ANI are fondly called presents a place having markedly different inter-communal societal relations in relation to the mainland India. Separated by the 1200 kilometers of water body called the Bay of Bengal, these Islands present a picture perfect mini India albeit without associated disharmony. Over the years the insurmountable distance from the mainland India, close contact among themselves, compulsion of undergoing rigorous life, absence of religious diktats have forced the humans to defy the stigmas of caste, creed and provincialism and a unique society was in the offing [22]. What is preached passionately in the mainland is practiced effortlessly here making the reading of Hindu-Muslim community an interesting research.

The society in the ANI has prima facie defied the cultural limitations. It overtly suggests that communication across traditions and cultures do not pose many problems when the meanings are general as well as universal. The pivotal component come across has been the innovation of emotionally and symbolically charged gestures of imperceptible universality [23]. The rootlessness of a being which otherwise may undermine the conscious and belittle the morale, has played a constructive role here. The common background of the early settlers and their descendents and uniformity of future interests have united them as homogeneous group of people. The religion which supposedly has emerged as one of the greatest divisive forces of history has unwittingly played a stabilizing role in the society which apparently is tremendously religious. The trends and relations may change sometime in future due to the forces of modernity and the present tradition of bonhomie and that of everyone knows everyone may no longer remain valid. Till the arrival of those times the rest of India may take a lesson or two from the Islanders.

\section{References}

1. Hobsbawm, Eric (1995) Introduction: Inventing Traditions, Cambridge University Press, Hyderabad, Telangana.

2. Truschke, Audrey (2015) Culture of Encounters: Sanskrit at the Mughal Court, Columbia University Press, New York, USA.

3. François Gautier (2015) The Unknown Similarities between Hinduism and Islam, India.

4. Sinha, Surjit Chandra (1952) Report on Survey of Further Possibilities of Resettlement.

5. Sen, Satadru (2000) Disciplining Punishment: Colonialism and Convict Society in Andaman Islands. 
6. Singh, Iqbal N, AK Ghosh (1978) The Andaman Story.

7. Khan, Iar Ali and SNH Rizvi (2014) The locals of port blair: a bio-cultural profile.

8. Brass, Paul R (2003) The production of hindu-muslim violence in contemporary India. University of Washington Press Washington, USA.

9. Imperial Gazetteer of India Provincial Series (1994) Andaman and Nicobar Islands.

10. Sen, Satadru, op cit, pp. 189-190.

11. Haughton to Home Department (1859) Government of India Home (Judicial). New Singh, op cit. pp. 165-187.

12. Iqbal, Rashida (1998) Who's Who? Port Blair: Directorate of Education and Culture, India.

13. Imperial Gazetteer of India, op. Cit, p. 65.

14. Ibid. p. 65.
15. Risely HH (1969) The People of India. Delhi, India.

16. Sen, Satadru. Op cit, p. 221.

17. Ibid. p. 222 .

18. Roychowdhury, Rabin (2011) The Untold Andaman and Nicobar Islands.

19. RSS vibhag pracharak Ashish Mondal (2015) There was also an instance of a government official named Majid in ANI who after independence was accused of trying to resettle 500 to 600 Muslims from East Bengal and therefore was suspected of trying to create an imbalance between Hindu and Muslim population and also of trying to ensure that Muslims became a majority. This instance is detailed in Iqbal N Singh, op cit, p. 282.

20. (2015) Interview with an Intelligence Bureau official.

21. Roychowdhury, Rabin. Op cit, p. 330.

22. Hobsbawm, op cit, p. 11. 